\title{
Environmental Risk Imposed by Diverted Flood Waters on Water and Soils in Emergency Retention Basins
}

\author{
Karl Erich Lindenschmidt ${ }^{1 *}$, Robert Harrison ${ }^{1}$, Martina Baborowski ${ }^{2}$ \\ ${ }^{1}$ Manitoba Water Stewardship, Surface Water Management, Winnipeg, Manitoba, Canada; ${ }^{2}$ Department of River Ecology, UFZ-Centre \\ for Environmental Research, Magdeburg, Germany. \\ Email: karl-erich.lindenschmidt@gov.mb.ca
}

Received December $6^{\text {th }}, 2009$; revised February $1^{\text {st }}$, 2010; accepted February $3^{\text {rd }}, 2010$.

\begin{abstract}
Emergency retention basins (ERB) are diked enclosures alongside rivers into which water from the main river channel is diverted during extreme floods. If the basins are operated during extreme flooding, two negative environmental impacts may occur: 1) contamination of the soils due to their transport by suspended sediments to the basin and 2) depletion of dissolved oxygen in the basin water. A computer-based methodology is presented which was used to assess the environmental risk exhibited by the operation of an ERB system proposed for the Elbe River in Germany. The August 2002 extreme flood event was used as a test case. For such a flood, the results showed that there is a 77\% risk that dissolved oxygen levels fall below $2 \mathrm{mg} / \mathrm{L}$ in the water and a 48\% chance of exceeding the inspection value of $500 \mathrm{mg}$ zinc/kg in the soil.
\end{abstract}

Keywords: Environmental Risk, Inundation, Retention Basins, Water Quality, Contaminated Soils, Quasi-2D Model

\section{Introduction}

The European Union (EU) has passed a Floods Directive to provide a legislative foundation for flood protection and mitigation in Europe. Since most large river basins in Europe extend over several countries, the directive will help to orient and broaden flood management efforts beyond the municipal and state authorities to the national and international levels and establish an improved and more cost-effective flood protection scheme (see also [1]). Interestingly, the directive includes many references to the environment and the EU Water Framework Directive, e.g.:

- Article 4 (Preliminary flood risk assessment): ... [must consider] potential adverse consequences for human health, the environment

- Article 9 (Flood hazard maps and flood risk maps): ... shall be coordinated with and may be integrated into the reviews provided for 2000/60/EC [WFD]

- $\quad$ Article 7 (Flood risk management plans): ... shall take into account costs and benefits, flood extent and conveyance routes, environmental objectives of 2000/60/EC [WFD], soil and water management

Hence, it will be mandatory to consider what impact new flood defence measures will have on the environment. Also, these measures are not to conflict with the goals of the EU WFD of achieving a good ecological status of water bodies.

After the extreme flood event along the Elbe River in August 2002, efforts were made to revamp flood management schemes in the river basin. Hence, the construction of an emergency retention basin (ERB) system has been proposed for the middle reaches of the Elbe River to reduce flood risk in the area [2].

Emergency retention basins are diked enclosures alongside rivers used to retain flood water by diverting and storing a portion of the river discharge during floods. The diversion from the main river channel to and from the ERBs is controlled in order to attain maximum capping of the peak discharge volume. The floodwater diversion reduces water levels downstream in the river and inundated areas and alleviates stress and damages in regions prone to high flood risk.

Studies on environmental risk assessment on retention basins by flood events are sparse in the literature. Therefore, the aim of the paper was to provide a possible computer modelling methodology on how such assessments can be tackled in fulfilling the proposed EU directives. Further, a preliminary assessment of the environment risk of heavy metal soil contamination and dissolved oxygen depletion in ERBs should be given. To solve these goals, excerpts have been drawn from [3-6].

In detail, the following steps were in the focus of the research: 
- develop and test a quasi-2D (two-dimension) model in which the equations of motion and continuity are calculated in 1D (one-dimension) but the discretisation scheme allows for a 2D representation of flow and substance distribution; this minimises computing and pre-processing expenditure without compensating spatial differentiation of flood behaviour,

- test how effective the proposed ERB system is able to cap the peak discharge of the hydrograph from the August 2002 flood,

- investigate the environmental risk of heavy-metal contamination of ERB soils after flood water retention, and

- assess the environmental risk of dissolved oxygen depletion in the water retained in the basins.

\section{Study Area}

Two ERBs were investigated in this studie, P1 and P3 (see Figure 1). They are situated between Torgau and Wittenberg. Morphological characteristics of the ERBs are given in Table 1. Several gates are to control the flow of water through the ERBs: an inlet gate at the southernmost tip of P1, an outlet gate at the westernmost point of P3 by Pretzsch and a connecting gate between $\mathrm{P} 1$ and $\mathrm{P} 3$.

Table 1. Morphological characteristics of emergency retention basins P1 and P3

\begin{tabular}{ccccc}
\hline Polder & $\begin{array}{c}\text { Surface area } \\
\left(\mathrm{km}^{2}\right)\end{array}$ & $\begin{array}{c}\text { Volume } \\
\left(10^{6} \mathrm{~m}^{3}\right)\end{array}$ & $\begin{array}{c}\text { Head } \\
(\mathrm{m} . \text { a.s.l. })\end{array}$ & $\begin{array}{c}\text { Depth } \\
(\mathrm{m})\end{array}$ \\
\hline P1 & 24.5 & 85 & 77.5 & 3.3 \\
P3 & 8.2 & 20 & 75.3 & 2.3 \\
\hline
\end{tabular}

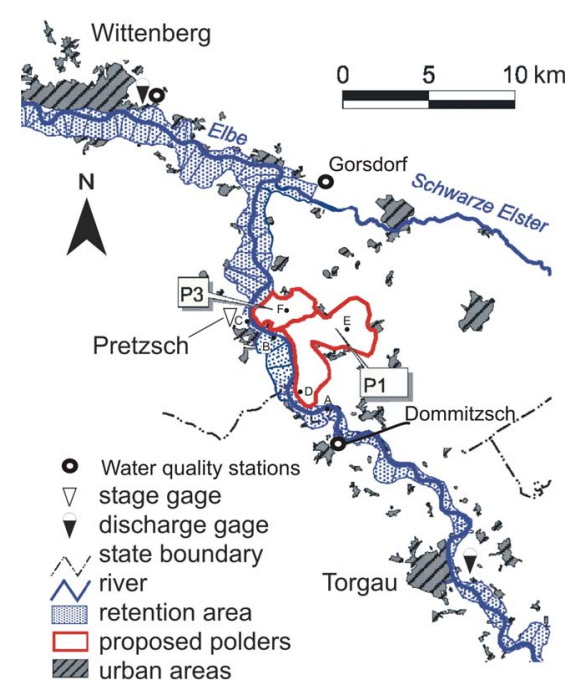

Figure 1. Investigated emergency retention basins (ERB) proposed for the Elbe River reach between Torgau and Wittenberg, modified from [2]

\section{Modeling Tool and Setup}

The hydrodynamic module DYNHYD (based on St. Venant equations), the sediment and contaminant transport module TOXI and the water-quality module EUTRO from the WASP5 (Water quality Analysis Simulation Program v.5) modelling package, developed by the U.S. Environmental Protection Agency [7] was used for the floodwater simulations. Figure 2 (left panel) shows the discretisation of the river-ERB system domain in junctions and channels. The junctions ensure volume continuity, hence all junction water volumes represent the total water volume in the system. The channels are the basis for computing the flow in 1D between the junctions. Many channels may branch from a junction allowing the discretisation to take a 2D characterisation. The segment discretisation for the contaminant transport and water-quality model, shown in Figure 2 (right panel), corresponds 1-to-1 the junction discretisation.

In TOXI, processes that describe the transport and fate of heavy-metal contaminants include:

- longitudinal dispersion in the water column,

- vertical diffusion of dissolved substances between the water column and the bottom sediments,

- sedimentation of suspended solids,

- re-suspension of solids from the bottom sediments to the water column, and

- sorption of dissolved substances to suspended and deposited sediments.

EUTRO was used to simulate water quality pertaining to the oxygen balance in a river and ERBs using the cycles of dissolved oxygen (DO) decomposition and nutrient-limited phytoplankton growth. Oxygen is also consumed in the sediments, which is described in the model by the sediment oxygen demand. An important source of oxygen into the water body is re-aeration via the water surface from the atmosphere.

An important source and sink of DO are phytoplankton photosynthesis and respiration, respectively. Phytoplankton growth is also light limited and its loss rate is governed by respiration, death, settling and zooplankton grazing.

The DYNHYD, EUTRO and TOXI modules were structured in a simulation platform HLA (High Level Architecture) to allow Monte-Carlo analyses (MOCA) to be carried out [8]. The MOCA allowed uncertainty bounds to be computed in order to assess the degree of risk in exceeding environmental thresholds. For the environmental risk appraisal the following were investigated: 1) the amount of zinc, with high contamination potential along the Elbe [9], sorbed and deposited from the diverted flood waters and 2) the minimum concentration of DO attained in the basin waters.

\section{Results}

For a comprehensive description of the development, 

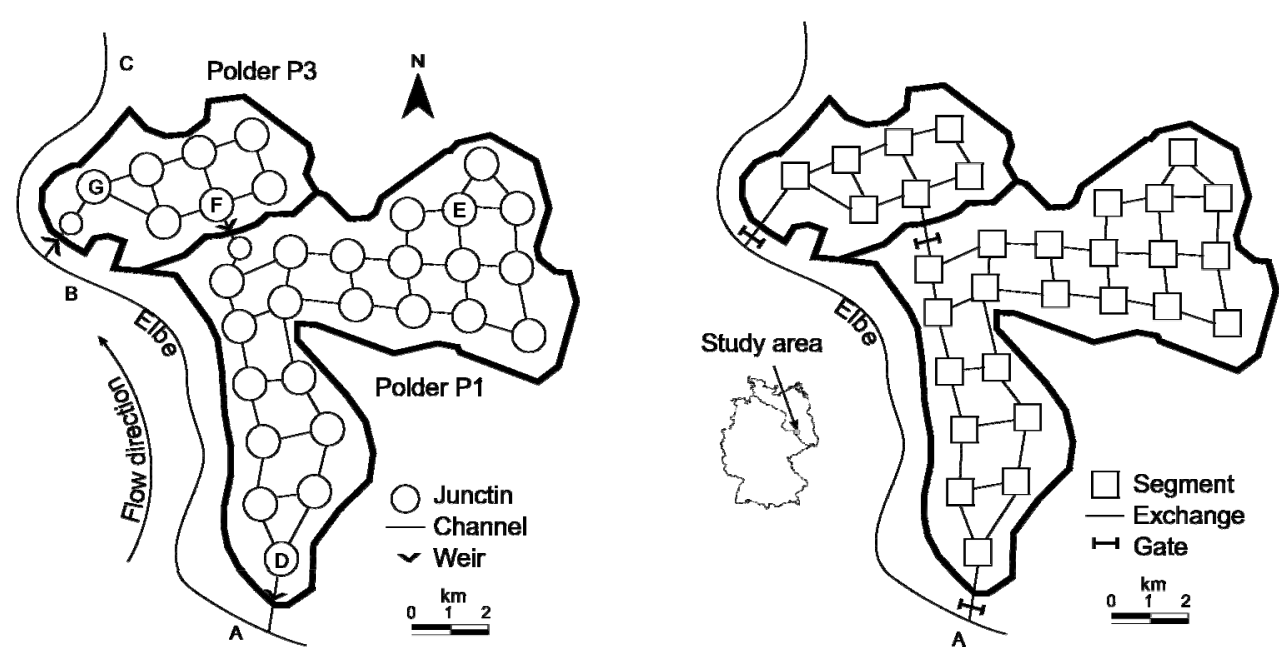

Figure 2. Discretisation for the hydrodynamic model with junctions and channels (left panel) and the water-quality model with segments (right panel), modified from [6] and [5]
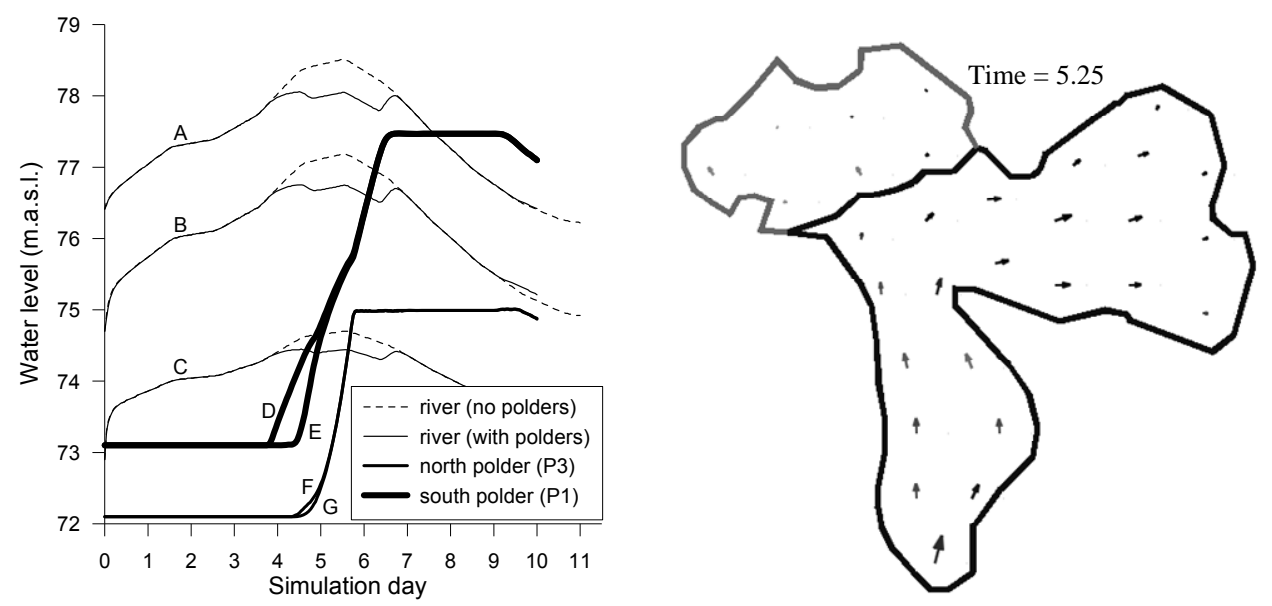

Figure 3. Left panel: water levels in the river and ERBs during operation. Right panel: flow velocity field in the ERBs during filling (longest vector length corresponds to $1.2 \mathrm{~m} / \mathrm{s}$ ), adapted from [6]

calibration and validation of the models with corresponding sensitivity analyses of the parameters and boundary conditions, the reader is referred to [6] for the hydrodynamic modelling, [4] for contaminant transport modelling and [5] for the eutrophication modelling. Only the key results to support the environmental assessments will be presented here.

\subsection{Hydrodynamics}

Figure 3 (left panel) shows the water level hydrographs of the August 2002 flood simulated along the river at Positions A, B and C (see Figure 2 for spatial reference). The dashed line of the hydrograph crests represent water level heights that occurred without the ERB system, the solid line represents the lowering of the water levels that can be obtained when the ERBs are included in the modelling. The capping lies in the range of 35 to $40 \mathrm{~cm}$ and progressively recedes as the flood wave moves down- stream (compare Position C). This is due to flood wave attenuation and widening of the floodplain downstream from Pretzsch towards Wittenberg (see Figure 1). Figure 3 (right panel) shows the 2D spatial differentiation of the flow field. Details on the development, calibration and validation of the model and the optimisation of the control of ERB filling are given in [4] and [6].

\subsection{Soil Contamination}

Figure 4 (left panel) shows the results of zinc concentrations in the river and ERBs. The initial concentrations in the ERB segments on the onset of water inflow correspond to the concentrations in the water in the immediate upstream-lying segments. Once the ERBs are filled and the flood gates are closed (approximately after Day 6 for P3 and after Day 7 for P1), there is a substantial drop in substance concentrations in the ERB water column due to sedimentation of suspended sediment. Up to $90 \%$ of 

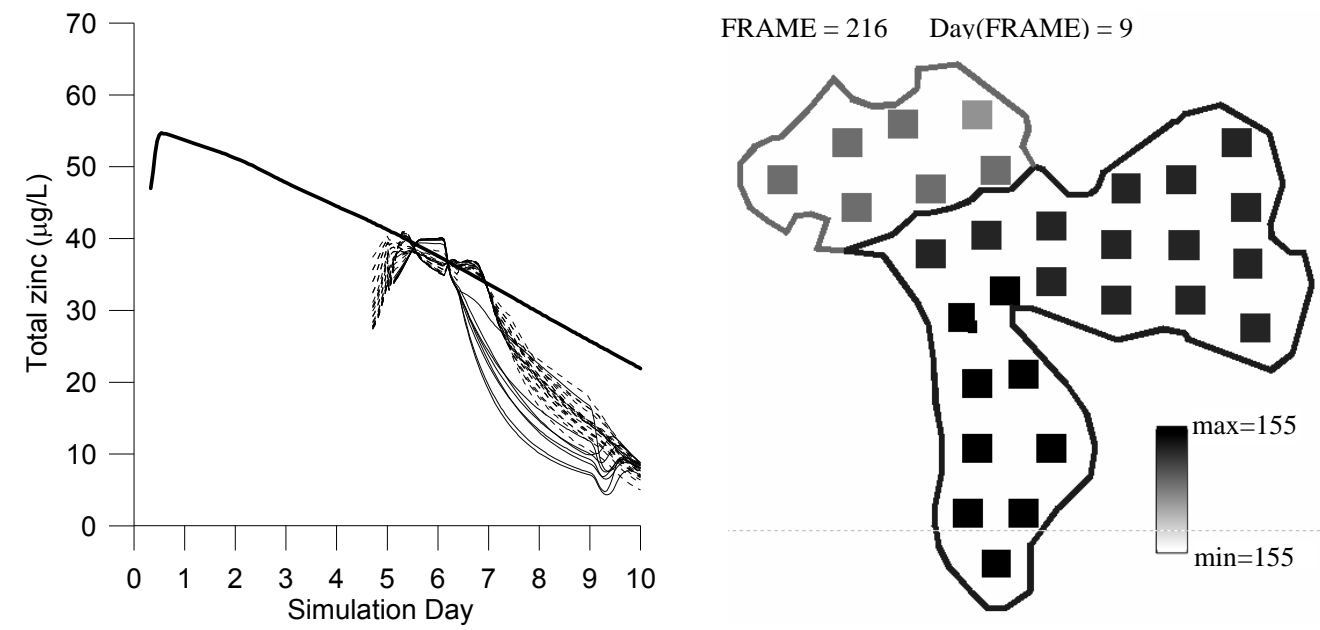

Figure 4. Total zinc (left panel) in the river at Position A (see Figure 2) and in ERBs P1 and P3. Zinc concentration (mg/kg) in bottom sediments during flood water retention [4]
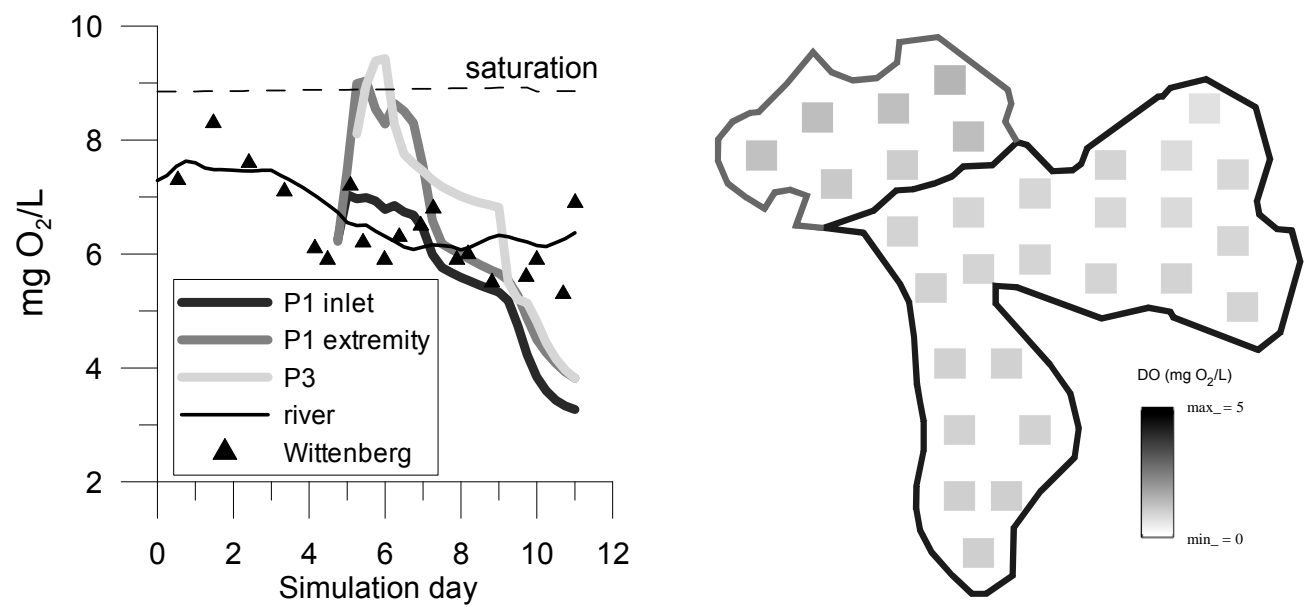

Figure 5. Left panel: DO concentrations in the river and ERBs during floodwater diversion. Right panel: lower $10 \%$ quartile of minimum DO at each segment throughout the ERB system [5]

the sediment settles out of the water column to the bottom sediments. Figure 4 (right panel) shows the spatial distribution of particulate zinc concentrations in the bottom sediments representing zinc deposition during the retention stage of flood water diversion. Particulate zinc is deposited quite quickly when water enters P1. Much of the particulate matter has also been trapped in P1 before the water enters P3. During flood water retention, zinc concentrations are evenly distributed throughout the ERB bottom sediments.

\subsection{Dissolved Oxygen Depletion}

Figure 5 (left panel) shows the DO simulations in the river at Wittenberg and in the ERBs. The DO levels in the river remain substantially below saturation levels. Upon entering the ERBs, diverted flood water receives more oxygen from the hydraulic re-aeration when pass- ing through the inlet gates. The initial flow of shallow waters during basin filling (Day 4 to 7 ) also contributes to the input of oxygen into the water. There is a progressive decline in DO concentrations during flood water retention (Days 8 and 9) which progresses into the emptying phase (after Day 9).

The lower decile of the minimum DO concentrations is shown spatially in Figure 5 (right panel). The DO levels are higher in P3 than in P1. The extremity (eastern bay) of P1 is generally less oxygenated than the remaining water in the ERB. It should be emphasised that the August 2002 simulation represents a best-case scenario. Additional factors that may impact DO negatively but were not included in the model are 1) higher sediment oxygen demand if surfaces are arable lands and not grasslands and 2) anoxia in the water-soil interface causing re-dissolution of inorganic nutrients from the ERB 
soils.

\section{Environmental Risk Assessment}

\subsection{Soil Contamination}

In order to make an environmental risk assessment of contamination in the ERBs, the deposition of pollutants onto the ERB surfaces must be placed within the legal context of the German sewage sludge ordinance. An example is given here using zinc as the heavy-metal contaminant. The ordinance provides threshold values of zinc content allowed in the soils and sediment ("sludge") deposited onto the land surfaces within the basins (summarised in Table 2).

In accordance to the German Sewage Sludge Ordinance, the background zinc concentrations in the soils, where the ERBs are to be situated, must be determined. The geogenic value of $150 \mathrm{mg}$ zinc/ $/ \mathrm{kg}$ sediment [10] for the Elbe catchment is used here for illustration. This value does not exceed the maximum allowable zinc content in the soils of $200 \mathrm{mg} / \mathrm{kg}$. Hence, sediment may be deposited from the river water diverted into the ERBs during extreme flooding. The content of zinc within the deposited sediment may not exceed $2500 \mathrm{mg} / \mathrm{kg}$, if the land surfaces are to continue to be used for agricultural purposes. Table 3 summarises the results from the MOCA showing that the probability of reaching this value is minute $(<1 \%)$. A different approach based on standards provided by the German Soil Protection and Contaminated Sites Ordinance is given in [5].

An important question that arises is how many floodings of the ERB can occur before the concentrations in the soil increase from the geogenic level of $150 \mathrm{mg} / \mathrm{kg}$ to the threshold value of $200 \mathrm{mg} / \mathrm{kg}$. Figure 4 (right panel) shows a spatial distribution of zinc bound to deposited sediment, which corresponds to an $8 \%$ exceedence probability extracted from the MOCA. The zinc content in the soil increases by $5 \mathrm{mg} / \mathrm{kg}$. Hence, approximately ten ERB floodings may cause zinc accumulation to reach the threshold value of $200 \mathrm{mg} / \mathrm{kg}$.

Although the environmental risk for zinc contamination is low, it should be noted that an amendment to the sewage sludge ordinance is currently being discussed in which the threshold values for allowed zinc content in soils and deposited sediment ("sludge") are lower (see Table 2). Careful measurements of the background zinc levels in the soils of the ERB sites should be carried out to determine how close these values are to the maximum allowable content in soils.

The environmental risk analyses presented here shows that there is minimal risk of plant contamination by zinc deposited onto the ERBs during floods. However, the risk may be substantially increased if the ERBs are located further downstream. Figure $\mathbf{6}$ shows the zinc content in deposited sediment along the portion of the Elbe River in Germany. Imbedded in the graph are the results

Table 2. Threshold values of zinc content in soils and deposited sediment ("sludge") as given by the German ordinances for sewage sludge

\begin{tabular}{lcl}
\hline & $\begin{array}{c}\text { mg zinc / kg } \\
\text { sediment }\end{array}$ & Comment \\
\hline $\begin{array}{l}\text { Sewage sludge ordinance } \\
\text { max. content in soil allowed }\end{array}$ & 200 & $\begin{array}{c}\text { soils with high clay content } \\
\text { soils with high clay content }\end{array}$ \\
$\quad$ max. content in sediment allowed & 2500 & \\
$\begin{array}{l}\text { Proposed amendments to the } \\
\text { sewage sludge ordinance }\end{array}$ & & \\
$\quad$ max. content in soil allowed & 150 & for loamy soils \\
$\quad$ max. content in sediment allowed & 1500 & \\
\hline
\end{tabular}

Table 3. Summary of the MOCA giving the probability of certain values of zinc in deposited sediments exceeding $50 \%, 16 \%$ and $1 \%$ in ERBs P1 and P3

\begin{tabular}{ccccc}
\hline \multirow{2}{*}{ Polder } & Units & \multicolumn{3}{c}{ Exceedence probability } \\
\cline { 3 - 5 } & & $50 \%$ & $16 \%$ & $1 \%$ \\
& & $(\mu)$ & $\approx(\mu+\sigma)$ & $\approx(\mu+3 \sigma)$ \\
\hline P1 & $\mathrm{mg} / \mathrm{kg}$ & 460 & 642 & 1000 \\
P3 & $\mathrm{mg} / \mathrm{kg}$ & 510 & 626 & 858 \\
\hline
\end{tabular}

$\mu$ - mean; $\sigma$ - standard deviation 


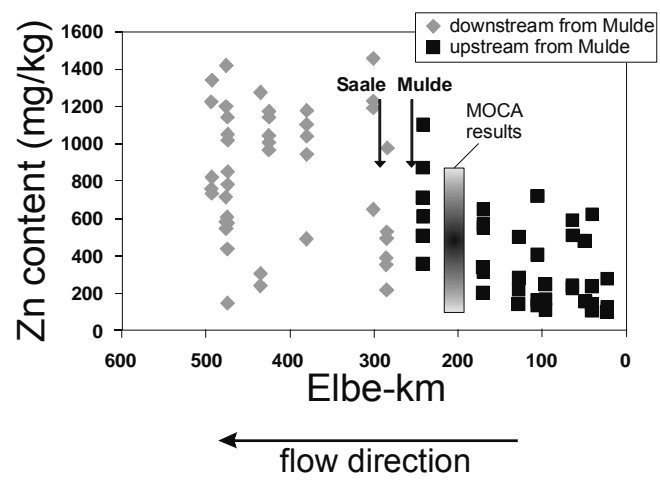

Figure 6. Longitudinal profile of zinc loading on soils along the Elbe River measured in 2003 after the extreme flood in the previous year, modified from [11], p. 242

obtained from the MOCA, the range of which complies with the range of all measurements taken upstream from the Mulde River inflow. For the river stretch downstream from the Mulde and Saale tributaries, the range and the maximum of zinc content in deposited sediments is twice as high as for the upstream reach.

\subsection{Dissolved Oxygen Depletion}

From the MOCA runs, probability distributions of the lowest DO levels attained in the ERBs during the simulation time frame were derived. The cumulative frequency distributions for three locations in the ERB system are shown in Figure 7. The threshold value of the minimum concentration of DO in inland waters used for a risk assessment is $3 \mathrm{mg} \mathrm{O} / / \mathrm{L}$-the minimum oxygen content with which most fish in the Elbe River can endure for a short term [12]. As soon as the oxygen content sinks below approximately $3 \mathrm{mg} / \mathrm{L}$, the fish begin to search for water pockets with better oxygen supply or begin to snap for air at the water surface [13].

For a summer time extreme flood such as the August

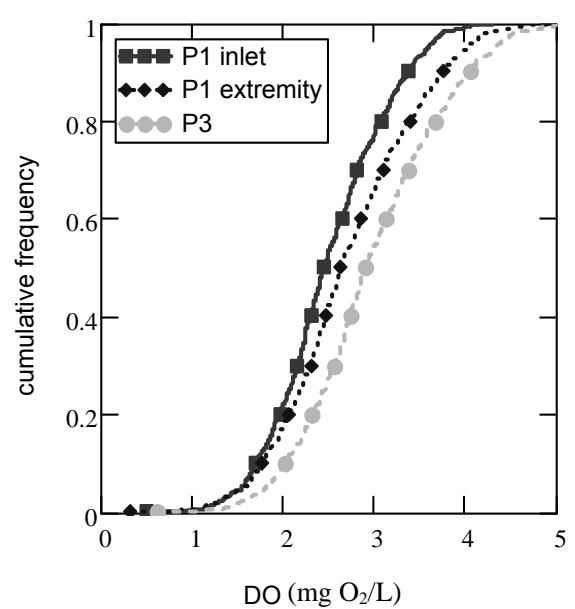

Figure 7. Cumulative frequency distributions of the lowest dissolved oxygen concentrations attained in the ERBs

2002 event along the Elbe, the probability of the DO values dropping below a threshold value of $3 \mathrm{mg} \mathrm{O}_{2} / \mathrm{L}$ is quite high, 77\% for the inlet region of P1, 65\% for the far eastern point of the P1 extremity and 54\% for P3 (see Figure 7). In general, the DO concentrations are higher more frequently in P3 than in P1 due to the shorter residence times of the water in this ERB and allowing less time for de-oxygenation of the water. The generally higher DO content in P3 is also due to its shallower depth, making it a more favourable aquatic environment for phytoplankton growth. The low DO values are also a result of low re-aeration (wind calm period) and high nitrification.

In contrast to experiences gained from the Havel River during the August 2002 flood, the low oxygenated water emptying into the River Elbe does not appear to have negative implications to the oxygen levels in the river water. Although the water of the Elbe River was under

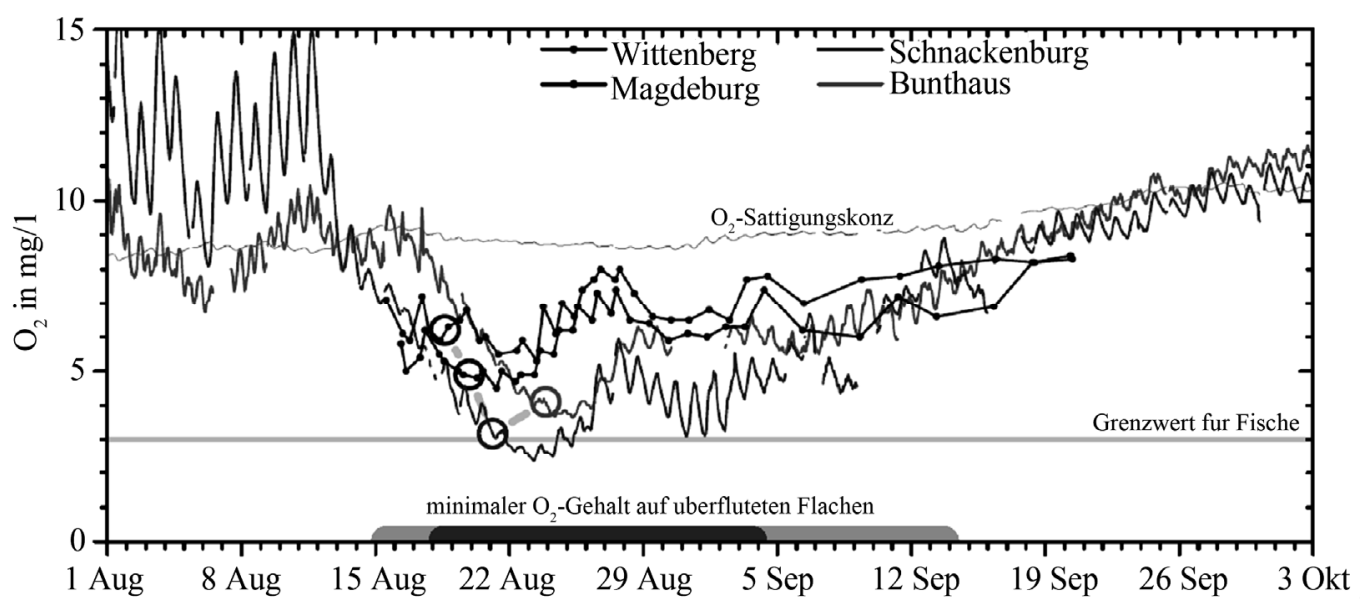

Figure 8. Dissolved oxygen concentrations at Wittenberg, Magdeburg, Schnackenburg and Bunthaus (last three locations $\approx$ 105,260 and $390 \mathrm{~km}$ downstream from Wittenberg) during the August 2002 flood of the Elbe River, adapted from [13] 
the DO saturation level, DO was still above the threshold value of $3 \mathrm{mg} / \mathrm{l}$ at Wittenberg (see Figure 8).

However, if these ERBs were situated further downstream where the DO concentrations of the river water fall below the threshold value, the emptied basin water could reduce the DO concentrations further and further stress the aquatic ecosystem.

\section{Conclusions}

The quasi-2D approach was successful in simulating the spatial distribution of flow and substance deposition in ERBs and determining the effectiveness of discharge capping. The environmental risk to heavy-metal contamination is minimal but may increase due to stricter threshold values. Risk may also be higher for ERBs constructed further downstream past the Saale and Mulde river confluences where exposure to contamination is higher. There is a high potential for DO levels in the water retained in the basins to drop to very critical levels (< $3 \mathrm{mg} \mathrm{O}_{2} / \mathrm{L}$ ), even after 4 days of flood water retention. From an ecological perspective, the basins should also be emptied as soon as possible after the flood in order to reduce the time of de-oxygenation of the water.

\section{REFERENCES}

[1] K.-E. Lindenschmidt, F. Hattermann, V. Mohaupt, B. Merz, Z. W. Kundzewicz and A. Bronstert, "Large-Scale Hydrological Modelling and the Water Framework Directive and Floods Directive of the European Union," Advances in Geosciences, Vol. 11, 2007, pp. 1-6.

[2] IWK, "Untersuchung von Hochwasserretentions maßnahmen entlang der Elbe im Bereich der Landkreis Wittenberg und Anhalt-Zerbst” (Kurzfassung), Institute für Wasserbau und Kulturtechnik, Universität Karlsruhe, 2004.

[3] K.-E. Lindenschmidt, "Quasi-2D Approach in Modelling the Transport of Contaminated Sediments in Floodplains during River Flooding-Model Coupling and Uncertainty Analysis,” Environmental Engineering Science, Vol. 25, No. 3, 2008, pp. 333-352.

[4] K.-E. Lindenschmidt, S. Huang and M. Baborowski, “A Quasi-2D Flood Modelling Approach to Simulate
Substance Transport in ERB Systems for Environmental Flood Risk Assessment," Science of the Total Environment, Vol. 397, No. 1-3, 2008, pp. 86-102.

[5] K.-E., Lindenschmidt, I. Pech and M. Baborowski, "Environmental Risk of Dissolved Oxygen Depletion of Diverted Flood Waters in River ERB Systems-A Quasi2D Flood Modelling Approach," Science of the Total Environment, Vol. 407, No. 5, 2009, pp. 1598-1612.

[6] S. Huang, J. Rauberg, H. Apel, M. Disse and K.-E. Lindenschmidt, "The Effectiveness of ERB Systems on Peak Discharge Capping of Floods along the Middle Reaches of the Elbe River in Germany," Hydrology and Earth System Sciences, Vol. 11, 2007, pp. 1391-1401.

[7] R. B. Ambrose, T. A. Wool and J. L. Martin, "The Water Quality Simulation Program,” Water Quality Analysis Simulation Program v.5, U.S. Environmental Protection Agency, Athens, GA, 1993.

[8] K.-E. Lindenschmidt, J. Rauberg and F. Hesser, "Extending Uncertainty Analysis of a Hydrodynamic-Water Quality Modeling System Using High Level Architecture," Water Quality Research Journal of Canada, Vol. 40, No. 1, 2005, pp. 59-70.

[9] M. Baborowski, W. von Tümpling and K. Friese, "Behaviour of Suspended Particulate Matter and Selected Trace Metals during the 2002 Summer Flood in the River Elbe at Magdeburg Monitoring Station,” Hydrology and Earth System Sciences, Vol. 8, No. 2, 2004, pp. 135-150.

[10] F. Krüger, A. Prange, E. Jantzen, K. Trejtnar and G. Miehlich, “Geogene Hintergrundwerte," Wasserwirts-chaftWassertechnik, Vol. 7, 1998, pp.16-19.

[11] W. Geller, K. Ockenfeld, M. Böhme and A. Knöchel (Eds.) "Schadstoffbelastung nach dem Elbe-Hochwasser 2002,” 2004, p. 460.

[12] ARGE-Elbe, “Gewässergütebericht der Elbe 2004,” Arbeitsgemeinschaft für die Reinhaltung der Elbe, 2005, p. 6.

[13] M. Böhme, F. Krüger, K. Ockenfeld and W. Geller, "Schadstoffbelastung nach dem Elbe-Hochwasser 2002,” 2005, p. 69. 